\title{
Comparison of coronary bypass surgery with and without cardiopulmonary bypass in patients with multivessel disease
}

\author{
Michael J. Mack, MD \\ Albert Pfister, MD ${ }^{\mathrm{d}}$ \\ Donna Bachand, $\mathrm{RN}, \mathrm{PhD}^{\mathrm{a}}$ \\ Robert Emery, MD ${ }^{\mathrm{C}}$ \\ Mitchell J. Magee, MDa \\ Mark Connolly, MD \\ Valavanur Subramanian, $\mathrm{MD}^{\mathrm{b}}$
}

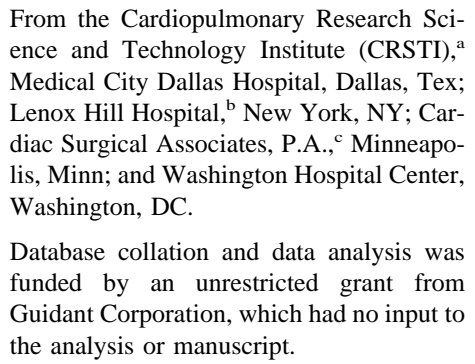

Received for publication Feb 14, 2003; revisions requested June 11, 2003; accepted for publication Aug 18, 2003.

Address for reprints: Michael J. Mack, MD, 7777 Forest Lane, Suite A323, Dallas, TX 75230 (E-mail: mjmack@earthlink.net).

J Thorac Cardiovasc Surg 2004;127:167-73 $0022-5223 / \$ 30.00$

Copyright (C) 2004 by The American Association for Thoracic Surgery

doi:10.1016/j.jtcvs.2003.08.032
Background: Coronary artery bypass grafting can now be performed with or without cardiopulmonary bypass. Our objective was to determine whether off-pump coronary artery bypass grafting is associated with better early outcomes compared with conventional coronary artery bypass grafting.

Methods: In 4 centers with off-pump coronary surgery experience, a retrospective analysis of all coronary artery bypass grafting in a 3-year period was performed. Groups were compared to determine selection criteria, mortality, and morbidity, then computer-matched by propensity score to control for selection bias. Multivariate logistic regression identified risk factors predictive of mortality. Specific subgroups most likely to benefit were identified.

Results: In all, 17,401 isolated coronary artery bypass grafts were performed, 7283 (41.9\%) off-pump coronary artery bypass grafts and 10,118 $(58.1 \%)$ conventional coronary artery bypass with cardiopulmonary bypass. Factors determining selection of patients for off-pump coronary artery bypass grafting included female gender $(55.5 \% \mathrm{vs}$ $44.5 \%$ ), preexisting renal failure ( $57.0 \%$ vs $43.0 \%)$, and reoperations ( $52.6 \%$ vs $47.4 \%$ ). Operative mortality was $2.8 \%$; off-pump coronary artery bypass grafting versus conventional coronary artery bypass with cardiopulmonary bypass $(1.9 \%$ vs $3.5 \%, P<$ .001 ) had the same predicted risk. Of the patients with multivessel disease, 11,548 were matched by propensity scoring. Mortality was significantly less in the off-pump coronary artery bypass grafting group $(2.8 \%$ vs $3.7 \%, P<.001)$. By multivariate logistic regression analysis of the matched sample, predictors for mortality were female gender (odds ratio 1.83, confidence interval 1.37-2.44), preexisting renal failure (odds ratio 2.85, confidence interval 2.64-4.95), history of stroke (odds ratio 1.74, confidence interval 1.08-2.80), previous coronary artery bypass grafting surgery (odds ratio 4.22, confidence interval 2.92-6.09), use of cardiopulmonary bypass (odds ratio 2.08, confidence interval 1.52-2.83), and recent myocardial infarction (odds ratio 2.31, confidence interval 1.68-3.22). Cardiopulmonary bypass was predictive of mortality in reoperations, female patients, and patients aged $\geq 75$ years. Off-pump coronary artery bypass grafting was associated with less morbidity, including reductions in blood transfusion $(32.6 \% \mathrm{vs}$ $40.6 \%, P<.001)$, stroke (1.4\% vs $2.1 \%, P=.002)$, renal failure $(2.6 \%$ vs $5.2 \%, P<$ $.001)$, pulmonary complications $(4.1 \%$ vs $9.5 \%, P<.001)$, reoperation $(1.7 \%$ vs $3.2 \%$, $P<.001)$, atrial fibrillation $(21.1 \%$ vs $24.99 \%, P<.001)$, and gastrointestinal complications $(3.6 \%$ vs $4.8 \%, P=.02)$.

Conclusion: In 4 centers with beating-heart operation experience, there is an overall early benefit in off-pump surgery, especially in patients traditionally considered at high risk for coronary artery bypass grafting. 


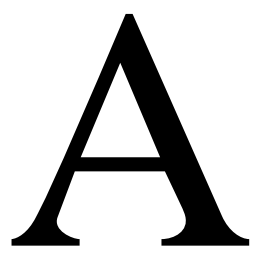

lthough initial surgical revascularization of the coronary arteries was performed on a beating heart in the 1960 s, the introduction of the heart-lung machine created optimal operative conditions of a bloodless, motionless operative field and allowed coronary artery bypass grafting $(\mathrm{CABG})$ to be done consistently with generally good results in most patients. ${ }^{1,2}$ Although a few centers persisted in applying beating-heart surgery in selective patients, the preponderance of $\mathrm{CABG}$ has been performed with cardiopulmonary bypass (CABGCPB) or "on-pump" over the past 35 years." ${ }^{3,4}$ Generally excellent results have been achieved with $\mathrm{CABG}$; however, significant mortality and morbidity still exist. ${ }^{5}$ In the mid1990s interest in beating-heart techniques experienced a resurgence in an attempt to decrease the morbidity associated with CABG without jeopardizing the benefits. Technological advancements significantly facilitated the performance of beating-heart surgery compared with the initial experience 30 years previously. ${ }^{6,7}$ Although estimates of the percent of CABG now performed by beating-heart approaches in the United States range from $20 \%$ to $25 \%$, only a few small single-center randomized trials exist comparing the results of coronary revascularization performed onpump (CABG-CPB) compared with off-pump (OP$\mathrm{CAB}) .^{8-10}$ Large, randomized trials comparing the 2 techniques have been difficult to perform due to the reluctance of patients, their referring physicians, and surgeons to participate in a randomized trial. Therefore, to assess the impact of beating-heart technique outcomes in CABG, the results of off-pump and on-pump coronary surgery were examined and compared in 4 large centers with significant beating-heart surgery experience (at least 5 years, 500 cases).

\section{Methods}

\section{Database Development}

The study employed a retrospective analysis of data pooled from 4 major cardiac surgery centers in the United States (Cardiopulmonary Research Science and Technology Institute, Medical City Dallas Hospital, Dallas, Tex; Lenox Hill Hospital, New York, NY; Cardiac Surgical Associates, PA, Minneapolis, Minn; Washington Hospital Center, Washington, DC). Centers were selected based on the volume of CABG cases performed per year and on surgeon experience with beating-heart techniques at each institution. The analysis was limited to the years 1999 through 2001 to limit possible bias associated with the centers' early learning experience. All patients undergoing initial or reoperative isolated $\mathrm{CABG}$ were included in the database.

In the 4 study centers, data were prospectively collected on all patients who had cardiac surgery; date were subsequently entered into a relational database. Three of the 4 centers used standardized criteria and definitions set forth by the Society of Thoracic Surgeons (STS) for measuring the study variables. ${ }^{5}$ The fourth institution collected data as mandated by the New York State Depart-
TABLE 1. Preoperative risk factors included in the database

- Age

- Gender

- Race

- Body mass index

- Congestive heart failure

- Chronic lung disease

- Renal failure

- Dialysis

- History of cerebrovascular accident

- Cerebrovascular disease

- Diabetes

- Peripheral vascular disease

- Ejection fraction

- Left main disease

- Myocardial infarction

- When myocardial infarction occurred

- Number of diseased vessels

- Previous coronary artery bypass grafting

- Surgical priority

- Parsonnet risk scores

ment of Health. Data from this institution were recoded as necessary to match the STS definitions. STS data elements that were not present in the New York State data set were eliminated. Data elements for which $10 \%$ or more data was missing were also excluded.

The resulting database consisted of 20 preoperative risk factors (Table 1). The Parsonnet risk stratification model was used to broadly define differences between treatment groups that might influence selection and patient outcomes. ${ }^{11}$ The Parsonnet risk stratification is a logistic regression model in which 47 potential risk factors are considered to determine risk preoperatively. This model is a tool to compare expected mortality rates with observed mortality. Perioperative data collected and compared between groups are listed in Table 2. Complete data were available for 17,401 patients during the study period, including $7283(41.9 \%)$ patients who underwent OPCAB and 10,118 (58.1\%) patients who underwent CABG-CPB. The total number of cases for each study center as well as the number and percent performed by each technique are listed in Table 3.

\section{Description of the Sample}

Patients were grouped and compared according to surgical treatment, OPCAB versus CABG-CPB. Preoperative patient characteristics and individual risk factors, intraoperative courses, and operative outcomes were compared by univariate and multivariate analyses using SPSS statistical software (SPSS Inc, Chicago, Ill). Data are reported as a percentage or as a mean \pm standard deviation. Univariate comparisons were computed using the Mantel-Haenszel chi-square test of general association unless otherwise stated. Fisher exact test was used in comparisons of small cell counts. Ordinal categorical data were compared using the Cochran-Armitage test for trends. Comparisons of continuous data were done using the Wilcoxon rank-sum test. All tests are two-sided.

Demographic characteristics and preoperative risk factors of the off-pump and on-pump groups were compared using chi- 


\section{TABLE 2. Outcomes included in the database}

- 30-day mortality

- Complications (yes or no)

- Septicemia

- Deep sternal wound infection

- Permanent neurologic deficit

- Transient stroke

- Perioperative myocardial infarction

- Reoperation for bleeding

- Reoperation for graft occlusion

- New-onset atrial fibrillation

- Cardiac arrest

- Anticoagulation complications

- Gastrointestinal complications

- Heart block

- Multisystem failure

- Cardiac tamponade

- Respiratory complication

- Renal failure

TABLE 3. Number of cases and proportion of OPCAB per study center

\begin{tabular}{cccr}
\hline Study center & $\begin{array}{c}\text { Total number of } \\
\text { CABG cases }\end{array}$ & $\begin{array}{c}\text { OPCAB } \\
\text { cases, } \mathbf{n} \\
\text { (\%) }\end{array}$ & \begin{tabular}{c}
\multicolumn{1}{c}{ CABG-CPB } \\
cases, $\mathbf{n}$ \\
(\%)
\end{tabular} \\
\hline A & 6105 & $2050(33.6)$ & $4055(66.4)$ \\
B & 4106 & $1199(29.2)$ & $2907(70.8)$ \\
C & 5931 & $2948(49.7)$ & $2983(50.3)$ \\
D & 1260 & $1086(86.2)$ & $174(13.8)$
\end{tabular}

OPCAB, Off-pump coronary artery bypass; $C A B G$, coronary artery bypass grafting; $C A B G-C P B$, coronary artery bypass grafting with cardiopulmonary bypass.

squared and Pearson $t$ test. Results indicated the groups were statistically different on several important characteristics (Table 4). Because the decision to perform CABG on- or off-pump at all 4 centers was at the surgeons' discretion, propensity score matching was conducted for treatment and control groups to control for selection bias. ${ }^{12,13}$

A multivariate logistic regression model was estimated to compute the probability of OPCAB selection for all multivessel cases in the sample. Independent variables used to create the model are listed in Table 5. A propensity score was calculated for each patient by solving the saturated model for the probability of off-pump bypass. Using only the propensity score, on-pump cases were matched to off-pump cases using a greedy matching strategy. For this procedure, matching to 5 decimal points was initially performed, followed by 4, 3, 2, and 1 decimal-point matching. Off-pump cases that could not be matched by propensity score within 1 decimal point with a comparable on-pump case were considered unmatched. The treatment-control matching procedure yielded a sample of 11,548 cases, with 5774 OPCAB and 5774 CABG-CPB subjects. Repeated analysis of the demographic characteristics and preoperative risk factors indicated that the OPCAB and $\mathrm{CABG}-\mathrm{CPB}$ groups were comparable in the matched sample.
TABLE 4. Differences in preoperative risk factors between unmatched study groups

\begin{tabular}{lccc}
\hline Risk factors & $\begin{array}{c}\text { On-pump } \\
\text { group (\%) }\end{array}$ & $\begin{array}{c}\text { Off-pump } \\
\text { group (\%) }\end{array}$ & $\boldsymbol{P}$ values \\
\hline CHF & 5.3 & 18.7 & $<.001$ \\
Chronic lung disease & 27.7 & 43.9 & $<.001$ \\
Renal failure & 2.6 & 3.2 & .05 \\
CVA & 4.9 & 6.1 & .004 \\
Cerebrovascular disease & 7.0 & 8.9 & $<.001$ \\
Peripheral vascular disease & 6.8 & 12.7 & $<.001$ \\
Previous CABG & 6.1 & 6.9 & $<.001$ \\
\hline
\end{tabular}

$C H F$, Congestive heart failure; CVA, cerebrovascular accident; $C A B G$, coronary artery bypass grafting.

TABLE 5. Independent variables used in propensity score matching

Gender

Renal failure

Hypertension

CVA

Congestive heart failure

Chronic lung disease

Peripheral vascular disease

Cerebrovascular disease

Previous CAB

MI

Left main disease

Surgical priority (elective, nonelective)

CVA, Cerebrovascular accident; $C A B$, coronary artery bypass; $M I$, myocardial infarction.

\section{Statistical Modeling}

Data from the matched sample were entered into a multivariate logistic regression model with mortality as the dependent variable. In this step, the backward elimination method was used to identify significant predictors of operative mortality from the set of 20 preoperative risk factors along with use of cardiopulmonary bypass as the independent variables. To identify subgroups most likely to benefit from beating-heart surgery, a series of alternate regression models were tested with mortality and major morbidities as dependent variables.

\section{Results}

In the 3-year period between 1999 and 2001, 17,401 isolated CABG procedures were performed in the 4 institutions. Cases with a concomitant procedure (eg, valve operations) were eliminated from this analysis. Volume of CABG procedures performed without cardiopulmonary bypass was $7283(41.9 \%)$ and ranged between $29.2 \%$ and $86.2 \%$ among the 4 institutions (Table 3 ). Factors predicting preferential selection are listed in Table 4. There were $12,761(73.4 \%)$ men and 4640 (26.6\%) women with a mean age $64.39 \pm 10.78$ (range 24-99). Reoperative procedures constituted $6.5 \%$ of the whole sample, $6.9 \%$ of the OPCAB group, and $6.1 \%$ of the $\mathrm{CABG}-\mathrm{CPB}$ cohort. Operative mor- 
TABLE 6. Parsonnet risk scores (mean/SD) for the propensity-matched sample

\begin{tabular}{lccc}
\hline & Score & $\begin{array}{c}\text { On-pump } \\
\text { group }\end{array}$ & $\begin{array}{c}\text { Off-pump } \\
\text { group }\end{array}$ \\
\hline Sample & $12.1(7.3)$ & $12(7.3)$ & $12.1(7.3)$ \\
Center A & $14.5(6.7)$ & $14.6(6.7)$ & $14.3(6.7)$ \\
Center B & $11.0(7.4)$ & $11.2(7.4)$ & $10.7(7.5)$ \\
Center C & $10.5(7.5)$ & $10.3(7.0)$ & $10.5(7.2)$ \\
Center D & $11.0(7.5)$ & $10.1(7.4)$ & $11.2(7.5)$ \\
\hline
\end{tabular}

TABLE 7. Predicted risk of mortality for the propensitymatched sample*

\begin{tabular}{lcc}
\hline & Mean (\%) & Standard deviation \\
\hline Sample & 6.39 & 5.88 \\
OPCAB & 6.46 & 5.91 \\
CABG-CPB & 6.33 & 5.86
\end{tabular}

$\overline{O P C A B}$, Off-pump coronary artery bypass; $C A B G-C P B$, coronary artery bypass grafting with cardiopulmonary bypass.

*Calculated from the logit of the Parsonnet score; formula published on the SFAR.org website.

tality of OPCAB versus CABG-CPB was $4.5 \%$ versus $11.6 \%$ in the reoperative group $(P<.001)$.

Overall mortality for the study population was $2.8 \%$. Parsonnet risk scores indicated no significant difference between the 2 groups (OPCAB vs CABG-CPB, 5.8 vs 6.6). Although Parsonnet risk scores predicted equal expected mortality in each group, observed mortality for the patients who underwent $\mathrm{CABG}-\mathrm{CPB}$ compared with OPCAB was $3.5 \%$ versus $1.9 \%(P<.001)$. Ten percent of the CABG procedures were single-vessel bypasses with $23.3 \%$ offpump and with a mortality of $0.9 \%$ compared with singlevessel operations performed with cardiopulmonary bypass with a mortality of $3.3 \%(P<.001)$. However, this higher mortality of single-vessel disease operated with cardiopulmonary bypass is explained by a higher portion of emergency/salvage patients in that group.

To minimize the role of selection bias, 11,458 multivessel disease patients were computer-matched by propensity scoring. The mean number of grafts per patient did not differ significantly between the 2 matched groups, 2.95 in the on-pump group and 2.83 in the off-pump group. Using the variables listed in Table 5, Parsonnet risk scoring of the 2 groups indicated identical predicted risks both in the whole sample and by institution as is indicated in Table 6 . Predicted risk of the propensity matched sample in each group is listed in Table 7. Despite the same predicted risk, the operative mortality was less in the OPCAB group $(2.0 \%$ vs $3.7 \%, P<.001)$. Multivariate logistic regression analysis of the propensity-matched sample indicated that the 6 variables in Table 8 were independent predictors of mortality,
TABLE 8. Predictors of mortality for the propensitymatched sample

\begin{tabular}{lccc}
\hline Variable & OR & CI & P value \\
\hline Female gender & 1.83 & $1.37-2.44$ & $<.001$ \\
Renal failure & 2.85 & $1.64-4.95$ & $<.001$ \\
CVA & 1.74 & $1.08-2.80$ & .02 \\
Redo & 4.22 & $2.92-6.09$ & $<.001$ \\
CPB used & 2.08 & $1.60-2.83$ & $<.001$ \\
Recent $\mathrm{MI}(<7$ days) & 2.31 & $1.68-3.22$ & $<.001$ \\
\hline
\end{tabular}

$O R$, Odds ratio; $C l$, confidence interval; $C V A$, cerebrovascular accident; $C P B$, cardiopulmonary bypass; $M I$, myocardial infarction.

TABLE 9. Predictors of mortality for the OPCAB group

\begin{tabular}{lccr}
\hline Variable & OR & CI & P value \\
\hline Female gender & 2.23 & $1.36-3.64$ & .001 \\
Dialysis & 5.94 & $1.97-17.87$ & .002 \\
Redo & 3.66 & $1.86-7.21$ & $<.001$ \\
Recent MI & 2.54 & $1.49-4.33$ & .001 \\
\hline
\end{tabular}

$\overline{O P C A B}$, Off-pump coronary artery bypass; $O R$, odds ratio; $\mathrm{Cl}$, confidence interval; $M I$, myocardial infarction.

including the use of $\mathrm{CPB}$ (odds ratio 2.08, confidence interval 1.52-2.83, $P<.001$ ).

Predictors of mortality in both groups included female gender, redo procedures, and recent myocardial infarction (Tables 9 and 10). Dialysis-dependent renal failure (but not non-dialysis-dependent renal insufficiency) was also a predictor in the off-pump surgery group while any preoperative renal failure, stroke, peripheral vascular disease, and remote myocardial infarction were also predictive in the on-pump group. A series of alternate models was tested for unique sets of predictors of mortality. CPB was predictive of mortality in patient age $\geq 75$ years, in patients undergoing reoperative $\mathrm{CABG}$, and in women (Table 11).

Chi-squared analysis documented significant reduction in mortality $(P<.001)$ as well as significant reductions in morbidity in the off-pump group, including: reduced total use of blood products $(P<.001)$, overall complications ( $P$ $<.001)$, permanent neurologic deficit $(P=.002)$, reoperation for bleeding $(P<.001)$, new-onset atrial fibrillation $(P$ $<.001)$, gastrointestinal complications $(P=.02)$, pneumonia $(P<.001)$, respiratory complications $(P<.001)$, and renal failure $(P<.001)$ (Table 12$)$. Further, it is noteworthy that the off-pump group experienced no increased incidence of any complication compared with the on-pump group.

\section{Discussion}

Evidence-based medicine mandates the prospective randomized trial as the most accurate tool for determining a treatment benefit compared with a control population. ${ }^{14,15}$ 
TABLE 10. Predictors of mortality for the CABG-CPB group

\begin{tabular}{lccc}
\hline Variable & OR & CI & $\boldsymbol{P}$ value \\
\hline Female gender & 1.74 & $1.21-2.49$ & .003 \\
Renal failure & 2.83 & $1.43-5.58$ & .003 \\
CVA & 2.00 & $1.12-3.57$ & .02 \\
PVD & 1.66 & $1.04-2.67$ & .04 \\
Redo & 4.70 & $3.03-7.36$ & $<.001$ \\
Old MI & 1.59 & $1.06-2.38$ & .03 \\
Recent MI & 2.18 & $1.43-3.33$ & $<.001$ \\
\hline
\end{tabular}

$C A B G-C P B$, Conventional coronary artery bypass with cardiopulmonary bypass; $O R$, odds ratio; $\mathrm{Cl}$, confidence interval; $\mathrm{CVA}$, cerebrovascular accident; $P V D$, peripheral vascular disease; $M I$, myocardial infarction.

Trial costs and delay in obtaining an answer notwithstanding, the generalizability of the results in a select study group to the treatment population as a whole can be questioned. ${ }^{16}$ Specific problems conducting a randomized prospective trial comparing on-pump with off-pump surgery include little experience and expertise in off-pump techniques in many major centers capable of randomizing patients and performing such a study. There are 3 prospective randomized studies comparing on- and off-pump CABG. ${ }^{8-10} \mathrm{~A}$ total of 879 patients combined have been enrolled in the 3 trials with an operative mortality of $0.9 \%$ in the on-pump group and $0.2 \%$ in the off-pump group. The outcomes for stroke in the same meta-analysis shows an incidence of $0.9 \%$ onpump and $0.4 \%$ off-pump. Both outcomes, however, are underpowered to show significance even in a meta-analysis.

There are many centers that have gained significant experience in off pump techniques. Consequently, their surgical expertise is relatively equal in both treatment arms (on vs off bypass). In these situations, there is an inability or unwillingness to randomize due to a perception of clinical benefit in off-pump surgery, either by the operating surgeon, the referring physician, or by the patients themselves who have frequently been referred to these institutions specifically for off-pump surgery. Hence, we hoped to gain insight into the impact of off-pump surgery on early CABG outcomes by a retrospective analysis using propensity score computer matching of cases from 4 institutions who had gained significant experience in beating-heart CABG. Although all the major risk factors for outcomes were able to be accounted for in the propensity matching, the role of the individual surgeon as a variable could not be included. Although all surgeons in each institution performed both on- and off-pump CABG, there was a predilection for some surgeons to perform a greater proportion off-pump while others performed a greater proportion on-pump. The individual surgeon is an independent variable affecting outcomes; however, in this analysis it was not possible to construct a propensity model that accounted for that variable.

The result of this analysis indicates that off-pump surgery is associated with significantly less operative mortality
TABLE 11. Predictors of mortality in specific subgroups

\begin{tabular}{lccc}
\hline Variable & OR & CI & P value \\
\hline Age $\geq 75^{*}$ & & & \\
$\quad$ Female gender & 1.99 & $1.15-3.46$ & .02 \\
Redo & 4.60 & $2.25-9.40$ & $<.001$ \\
$\quad$ CPB used & 2.13 & $1.20-3.76$ & .01 \\
Redo CABG $†$ & & & \\
Dialysis & 17.87 & $9.95-32.07$ & .05 \\
CVA & 3.08 & $1.04-9.13$ & .04 \\
Recent MI & 3.12 & $1.39-7.00$ & .006 \\
CPB Used & 3.37 & $1.59-7.17$ & .002 \\
Women & & & \\
Dialysis & 4.57 & $1.79-11.7$ & .002 \\
CVA & 2.02 & $1.0-4.1$ & .05 \\
Recent MI & 2.7 & $1.65-4.73$ & $<.001$ \\
CPB Used & 1.7 & $1.07-2.69$ & .02 \\
Redo & 3.88 & $1.94-7.76$ & $<.001$
\end{tabular}

$O R$, Odds ratio; $\mathrm{Cl}$, confidence interval; $C P B$, cardiopulmonary bypass; $C V A$, cerebrovascular accident; $M I$, myocardial infarction.

${ }^{*} \mathrm{n}=1479(20 \%$ of sample $)$.

tn $=460(6.2 \%$ of sample $)$.

$\ddagger \mathrm{n}=1929(26.1 \%$ of sample $)$.

and morbidity than on-pump surgery and that the use of cardiopulmonary bypass is an independent risk factor for mortality in centers that have attained significant experience with beating-heart techniques.

A significant shortcoming of this study is that the format of the data collection tool does not allow for an intentionto-treat analysis. On occasion, due to intraoperative hemodynamic instability or technical issues limiting access to target coronary vessels, conversion from off-pump to onpump is necessary to complete the procedure. Prior to the year 2000, the STS database, which was the collection tool in 3 of the 4 centers, did not collect conversion from off-pump to on-pump surgery data. Hence, in these 3 institutions in 1999, analysis of patients whose operation was initiated off-pump and converted intraoperatively to the use of cardiopulmonary bypass were included in the on-pump group, thereby conceivably adversely affecting the outcomes of the CABG-CPB cohort. Therefore, to determine how this factor might impact the data, the database was analyzed separately for the years 2000 and 2001, for which conversion data was available for all 4 centers. This allowed analysis for patients in 2000 and 2001 to be included on an intention-to-treat basis, including the OPCAB conversions with the OPCAB group. The conversion rate was $2.9 \%$ and including these 172 patients with the off-pump group rather than the on-pump group for analysis resulted in no significant differences in outcomes.

It is also important to note that these data include only early procedural outcomes and do not address longer-term follow-up. Despite early improved outcomes in operative mortality and morbidity, long-term graft patency and eventfree survival remain unknown. Although early angiographic 
TABLE 12. Outcomes from the propensity score-matched sample

\begin{tabular}{|c|c|c|c|c|}
\hline Outcome & Sample, n (\%) & CABG-CPB, n (\%) & OPCAB, n (\%) & $P$ value* \\
\hline Use of blood products & $4659(47.0)$ & $3156(40.6)$ & $1503(32.6)$ & $<.001$ \\
\hline Complications & $4093(40.9)$ & $2997(56.0)$ & $1096(23.5)$ & $<.001$ \\
\hline Septicemia & $56(0.6)$ & $41(0.8)$ & $15(0.3)$ & .002 \\
\hline Deep sternal wound infection & $51(0.4)$ & $33(0.6)$ & $18(0.3)$ & .02 \\
\hline Permanent neurologic deficit & $202(1.7)$ & $123(2.1)$ & $79(1.4)$ & .002 \\
\hline Transient stroke & $48(0.6)$ & $26(0.6)$ & $22(0.5)$ & NS \\
\hline Perioperative $\mathrm{MI}$ & $119(1.0)$ & $75(1.3)$ & $44(0.8)$ & .005 \\
\hline Reoperation for bleeding & $248(2.5)$ & $169(3.2)$ & $79(1.7)$ & .001 \\
\hline Reoperation for graft occlusion & $15(0.2)$ & $7(0.1)$ & $8(0.2)$ & NS \\
\hline New-onset A-fib & $2644(23.1)$ & $1439(25.0)$ & $1205(21.1)$ & $<.001$ \\
\hline Cardiac arrest & $145(1.3)$ & $92(1.6)$ & $53(0.9)$ & .001 \\
\hline GI complications & $487(4.2)$ & $277(4.8)$ & $210(3.6)$ & .004 \\
\hline Multisystem failure & $49(0.5)$ & $33(0.6)$ & $16(0.3)$ & .04 \\
\hline Cardiac tamponade & $89(0.8)$ & $56(1.0)$ & $33(0.6)$ & .02 \\
\hline Pneumonia & $318(2.8)$ & $206(3.6)$ & $112(2.0)$ & $<.001$ \\
\hline Pulmonary embolus & $38(0.3)$ & $18(0.3)$ & $20(0.3)$ & NS \\
\hline Respiratory complication & $787(6.8)$ & $551(9.5)$ & $236(4.1)$ & $<.001$ \\
\hline Renal failure & $453(3.9)$ & $300(5.2)$ & $153(2.6)$ & $<.001$ \\
\hline Mortality & $327(2.8)$ & $211(3.7)$ & $116(2.0)$ & $<.001$ \\
\hline
\end{tabular}

$C A B G-C P B$, Conventional coronary artery bypass with cardiopulmonary bypass; OPCAB, off-pump coronary artery bypass; $M I$, myocardial infarction; $A$-fib, atrial fibrillation; $G I$, gastrointestinal. One center records respiratory failure rather than pulmonary embolus or pneumonia; respiratory complication is a composite variable that includes pneumonia, pulmonary embolus, or respiratory failure. If a subject experienced any one of these complications, then respiratory complication $=$ yes.

${ }^{*} P$ values in comparison of CABG-CPB and OPCAB categories.

graft patency has been demonstrated to be excellent, ${ }^{17}$ an intermediate-term study is not as definitive. ${ }^{18}$ A subgroup studied at 3 years demonstrates excellent left internal thoracic artery graft patency, but saphenous vein graft patency to the posterior circulation using early generation stabilization and exposure techniques was lower than one would expect.

Certain results are worthy of note. The first is that the use of cardiopulmonary bypass is an independent risk factor for mortality. Second, there appears to be a particular benefit to avoiding CPB in those subgroups generally considered high risk for CABG surgery, including the elderly, women, and patients undergoing reoperative operations. Third, as well as a mortality benefit, the performance of beating-heart surgery is associated with a significant decrease in perioperative morbidity including the need for blood transfusions, return to the operating room for bleeding, respiratory complications, and new-onset renal failure. A further potential benefit of beating-heart surgery was hoped to be improved neurologic outcomes. Indeed, this analysis demonstrates a significant decrease in permanent neurologic deficit postoperatively in the OPCAB group $(1.4$ vs $2.1, P<.001)$.

Definitive outcomes analysis awaits a multicenter prospective randomized trial. However, due to the low incidence of major adverse outcomes (eg, mortality, stroke), such a study would require many thousands of patients to confer adequate statistical power to detect differences between on- and offpump treatment groups. The only such study currently under- way is the Veteran's Administration cooperative study but it will be many years before this study is completed and analyzed and results made available for evaluation. Even then, those results will be limited by the population studied as well as the inexperience in beating-heart techniques in many of the centers. This study represents significant experience on the part of centers who are extremely experienced and proficient in this operation. These centers have advanced past learning curves and represent a mature application of this technology. These data, despite their methodological shortcomings, support a benefit for $\mathrm{OPCAB}$, which is consistent with numerous previous reports. In addition, OPCAB benefit persists despite elevated risk among those patients preferentially operated on off-pump. Ability to achieve superior outcomes in high-risk patients in terms of mortality and across a number of morbidity variables clearly speaks to the potential clinical benefit of this operation. Although not randomized, this study adds to the increasing body of patients and among sample sizes sufficient to confer adequate statistical power for detection of differences.

We thank the Cardiopulmonary Research Science and Technology Institute (CRSTI), Medical City Dallas Hospital, Dallas, Tex; Sherry Mullins, Lenox Hill Hospital, New York, NY; Rita Considine, RN, MS, Joan Jennings, RN, MA, Cardiac Surgical Associates, PA, Minneapolis, Minn; Carla Erickson, RN, MS, Washington Hospital Center, Washington, DC; and Leanne McKenna, RN. 


\section{References}

1. Kolessov VI. Mammary artery coronary artery anastomosis as method of treatment for angina pectoris. J Thorac Cardiovasc Surg. 1967;54: 535-44.

2. Favaloro RG, Effler DB, Groves LK, Shelton WC, Sones FM Jr. Direct myocardial revascularization by saphenous vein graft. Present operative techniques and indications. Ann Thorac Surg. 1970;10:97-111.

3. Buffolo E, de Andrade JCS, Branco JNR, et al. Coronary artery bypass grafting without cardiopulmonary bypass. Ann Thorac Surg. 1996;61: 63-6.

4. Pfister AJ, Zaki MS, Garcia JM, et al. Coronary artery bypass without cardiopulmonary bypass. Ann Thorac Surg. 1992;54:3085-92.

5. The Society of Thoracic Surgeons (STS). National Cardiac Surgery Database (http://www.ctsnet.org/doc/4314).

6. Subramanian VA, Sani G, Benetti FJ, Calafiore AM. Minimally invasive coronary bypass surgery: A multi-center report of preliminary clinical experience [abstract]. Circulation. 1995;92:S645.

7. Jansen EW, Borst C, Lahpor JR, et al. Coronary artery bypass grafting without cardiopulmonary bypass using the octopus method: results in the first one hundred patients. J Thorac Cardiovasc Surg. 1998;116: 60-7.

8. Angelini GD, Taylor FC, Reeves BC, et al. Early and midterm outcomes after off-pump and on-pump surgery in beating heart against cardioplegic arrest studies (BHACAS 1 and 2): a pooled analysis of two randomized controlled trials. Lancet. 2002;359:1194-9.

9. Puskas JD, Willliams WH, Duke PG, et al. Off-pump coronary artery bypass grafting provides complete revascularization with reduced myocardial injury, transfusion requirements, and length of stay: a prospective randomized comparison of two hundred unselected patients undergoing off-pump versus conventional coronary artery bypass grafting. J Thorac Cardiovasc Surg. 2003;125:797-808.

10. van Dijk D, Nierich AP, Jansen EWL, et al. Early outcome after off-pump versus on-pump coronary bypass surgery. Circulation. 2001; 104:1761-6.

11. Bernstein A, Parsonett V. Bedside estimation of risk as an aid for decision-making in cardiac surgery. Ann Thorac Surg. 2000;69:823-8.

12. D'Agostino RB Jr. Propensity score methods for bias reduction in the comparison of a treatment to a non-randomized control group. Stat Med. 1998;17:2265-81.

13. Rubin DB. Estimating causal effects from large data sets using propensity scores. Ann Intern Med. 1997;127:757-63.

14. Cairns J, Camm J, Fallen E, Gersh B, Yusuf S. Evidence based cardiology. In: Yusuf S, Camm J, editors. BMJ books. Tavistock Square, London: BMA House; 1998. p. 17-28.

15. Pocock SJ, Elbourne DR. Randomized trials or observational tribulations? N Engl J Med. 2000;342:1907-9.

16. Conato J, Shah N, Horwitz RI. Randomized, controlled trials, observational studies, and the hierarchy of research design. $N$ Engl J Med. 2000;342:1887-92.

17. Puskas JD, Thourani VH, Marshall JJ, et al. Clinical outcomes, angiographic patency, and resource utilization in 200 consecutive off pump coronary bypass patients. Ann Thorac Surg. 2001;71: 1477-84.

18. Omeroglu SN, Kirali K, Guler M, Toker ME, Ipek G, Isik O, et al. Midterm angiographic assessment of coronary artery bypass grafting without cardiopulmonary bypass. Ann Thorac Surg. 2000;70: 844-50.

\section{Availability of Journal back issues}

As a service to our subscribers, copies of back issues of The Journal of Thoracic and Cardiovascular Surgery for the preceding 5 years are maintained and are available for purchase from Elsevier Inc. until inventory is depleted. Please write to Elsevier Inc., Subscription Customer Service, 6277 Sea Harbor Dr, Orlando, FL 32877 , to or call $800-654-2452$ or $407-345-4000$ for information on availability of particular issues and prices. 